\title{
A systems approach to investigate the rigidity of intermodal transport systems
}

DOI:

10.2514/6.2011-7009

Link to publication record in Manchester Research Explorer

\section{Citation for published version (APA):}

Steele, A., \& Hollingsworth, P. (2011). A systems approach to investigate the rigidity of intermodal transport systems. In 11th AlAA Aviation Technology, Integration, and Operations (ATIO) Conference, including the AIAA Balloon Systems Conference and 19th AlAA Lighter-Than-Air Technology Conference/11th AIAA Aviation Technol. Integration and Operat. (ATIO) Conf. including the AIAA Balloon Syst. Conf. and 19th AIAA Lighter American Institute of Aeronautics and Astronautics . https://doi.org/10.2514/6.2011-7009

\section{Published in:}

11th AIAA Aviation Technology, Integration, and Operations (ATIO) Conference, including the AIAA Balloon Systems Conference and 19th AIAA Lighter-Than-Air Technology Conference|11th AIAA Aviation Technol. Integration and Operat. (ATIO) Conf. including the AIAA Balloon Syst. Conf. and 19th AIAA Lighter

\section{Citing this paper}

Please note that where the full-text provided on Manchester Research Explorer is the Author Accepted Manuscript or Proof version this may differ from the final Published version. If citing, it is advised that you check and use the publisher's definitive version.

\section{General rights}

Copyright and moral rights for the publications made accessible in the Research Explorer are retained by the authors and/or other copyright owners and it is a condition of accessing publications that users recognise and abide by the legal requirements associated with these rights.

\section{Takedown policy}

If you believe that this document breaches copyright please refer to the University of Manchester's Takedown Procedures [http://man.ac.uk/04Y6Bo] or contact uml.scholarlycommunications@manchester.ac.uk providing relevant details, so we can investigate your claim.

\section{OPEN ACCESS}




\title{
A Systems Approach to Investigate the Rigidity of Intermodal Transport Systems
}

\author{
A. Steele ${ }^{1}$ and P. Hollingsworth ${ }^{2}$ \\ The University of Manchester, Manchester, England, M13 9PL
}

\begin{abstract}
Disturbances within the European transport system have recently generated millions of pounds worth of damages and caused widespread passenger delays. The Eyjafjallajökull volcanic eruption demonstrated how a large scale disturbance within one transport sector can cause a series of knock on effects through other modes of transport, which were illequipped to deal with a significant fluctuation in demand. The cascading effects are a result of the rigid nature of the transport system caused by its complex structure and a lack of suitable preparation. Predicting the behaviour of complex systems is both costly and time consuming due to their data intensive nature. Additionally the transport system is dynamic and it is difficult to perform suitable quantitative analysis. A major challenge is to develop a system that can predict the changes in passenger demand between different modes of transports during a disturbance on one or more of these systems, which will enable the transport industry to implement suitable policies to cope with unexpected demand. This work suggests and analyzes a systems dynamics method incorporating impact analysis techniques which attempts to model and predict the rigid behaviour of an intermodal transport system. The intention of which is to design a predictive tool that can help forecast the direction and magnitude of passenger movement. This paper introduces the concept through the development and initial testing of a simplified dual-mode UK transport model created using system dynamics software. The model is tested with reference to data collected from the recent disturbances and thus suggests its potential predictive uses. As the model is still in the early stages of development further improvements are suggested and the benefits and drawbacks of the approach are discussed.
\end{abstract}

\section{Introduction}

$\mathrm{A}$ SYSTEM of systems is a complex structure developed from numerous self contained systems, each capable of operating autonomously, that interact with each other through a series of relationships and linkages. These systems are notoriously difficult to analyze due to their emergent and evolutionary behaviour generating complex and often unpredictable interrelationships between each system. As such, systems of systems are often difficult to predict and large levels of uncertainty surround their performance characteristics ${ }^{1}$. Complex systems are found through many disciplines, developing from industry ${ }^{2}$ into diverse fields such as biology ${ }^{3}$ and climatology ${ }^{4}$. Consequentially, a number of negative traits associated with the behaviour can be seen within complex systems.

Rigidity within the transport system arises due to the nature of the complex interrelationships between different transport modes. Due to the reliance of each transport mode on another, a large disturbance can cause widespread closures and delays, with large costs associated with system recovery. As each system was designed separately the interrelationships have developed over time meaning they tend to be dynamic, hence fluctuations in the relationships can depend on a number of factors largely based around human behaviour and trends. The complex behaviour of

\footnotetext{
${ }^{1}$ Student, School of Mechanical, Aerospace and Civil Engineering, AIAA Student Member

${ }^{2}$ Lecturer, School of Mechanical, Aerospace and Civil Engineering, AIAA Member.
} 
intermodal relationships have made the transport system rigid, meaning each transport mode can influence the other and as a result any disturbance to one system can have knock on effects throughout the system.

The transport system in the UK is one of the most complicated and extensive transport systems in the world, with access readily available to most types of public transport and a number of international airports and ferry terminals. In 2009, 218 million passengers travelled through British airports of which 20.9 million were domestic services. Further to this, worldwide, London Heathrow (LHR) had the largest number of terminal passengers on international flights in 2009 at 60.7 million $^{5}$. Further to this, 1,258 million rail journeys were made within the UK in 2009/10 despite a drop of 1.3 percent from the previous year. The total receipts for all franchised operators totaled $£ 6,179$ million from the rail service alone. Additionally, there were 85,800 public service vehicles in use completing a total of 50 billion passenger kilometers in 2009 , as well as 186.2 million passenger journeys by light railway and tram services ${ }^{6}$. This data shows the economic and social importance of the public transport system in the UK and demonstrates the necessity to respond quickly to disturbances by having suitable contingency policies.

Recent events have demonstrated this and highlighted the need for suitable predictive tools and policies to prevent serious economic loss. Events such as the British Airways strikes throughout 2010 and $2011^{7}$ and the tragedy of September $11^{\text {th }} 2001^{8}$, have all generated significant delays and have had serious financial implications for the transport industry as a whole. Had these events been previously planned for, suitable actions could have been devised in order to mitigate the losses and minimise the delays for travelers.

The Eyjafjallajökull volcanic eruption starting on the $20^{\text {th }}$ March $2010^{9}$ demonstrated how a natural disaster can bring a large interconnected, intermodal transport system to a standstill. Due to the weather conditions on the $14^{\text {th }}$ April 2010; the time of the second and most explosive stage of the eruption, the ash plume generated caused large sections of the European aviation industry to close. This left many passengers stranded across the globe and created unexpected increase in the demand for alternative transport modes and as such had cascading delays throughout the transport system. Within the UK, 23 of the 24 major UK airports were closed for at least a week and it was estimated by the International Air Travel Association (IATA) that on the $20^{\text {th }}$ April 2010 that carriers were losing over $\$ 200$ million per day 9 .

This demonstrated the fragility of the UK transport system and the need for a method to predict and analyze potential impacts. In order to reduce the impact on the transportation system during unexpected events such as this the international community has suggested implementing new or modifying existing policies for air travel. These policies can often also have unexpected consequences, potentially adding to the problem rather than providing a solution, therefore it highlights a further need for an accurate model to predict potential impacts within the system. The reason for this counterintuitive behaviour is due to the complex structure responding unexpectedly to simple, intuitive assumptions.

Historically, different modeling techniques such as mathematical modelling ${ }^{10}$ and agent based simulation ${ }^{11}$ have been used to investigate different behaviors within the transport system. Statistical based modeling programs used in mathematical are restricted in their use due to limitations in demonstrating human behaviour.

System Dynamics ${ }^{2}$ offers a method of modeling the transport industry in such a way that the complex interrelationships between each component and sub component of the system can be modeled. Once a suitable model is developed a variety of impact analysis scenarios could be implemented on the system. Developing detailed, accurate models such as this could help prepare the industry for disturbances of all sizes, from a single aircraft being delayed to another significant volcanic eruption. If a suitable system dynamics model existed, the scenario could be input and different policies or responses could be devised in order to respond to the disturbance. This systems dynamics model could offer the solution which will optimize the use of the transport system and reduce delays as much as possible.

This work analyzes the use of System Dynamics to investigate how a disturbance influences passenger movements between different modes of transport within the same system. The aim of this work is to demonstrate the use of System Dynamics for use as a predictive tool to simulate potential disasters in order to forecast the movement of passengers between the different modes during times of disturbance. The approach will be demonstrated through a simplified model of a multi-modal transport system involving two transport systems and the implementation of a basic impact model. The impact model will be used to simulate scenarios to show how the movements of passengers around the system will change and, through comparison with real life data regarding the Eyjafjallajökull volcanic eruption, a conclusion on the suitability of the technique can be drawn. 


\section{System Dynamics \& Impact Analysis}

\section{A. System Dynamics}

Systems that have multiple components or subsystems can be described as complex. A complex system often has very complicated interrelationships between the different subsystems, which can mean modeling these systems is very difficult. System dynamics is a method used to model complex structures to investigate the intricate relationships between large dynamic systems and small subsystems. Suitable models can clearly show how an effect on one system can affect entire complex system as a whole.

System dynamics applies to dynamic problems arising in complex social, managerial, economic or ecological systems, which are characterized by interdependence, mutual interaction, information feedback and circular causality. These feedback systems can be considered complex and decision making processes within systems, such as a company or transport sector, can lead to unexpected results. ${ }^{12}$

Complexity can develop within systems in two main ways; combinatorial complexity and dynamic complexity ${ }^{12}$. Combinatorial complexity is generated in larger systems where the complexity lies in finding the most suitable solution through an astronomical number of possibilities. Dynamic complexity however can arise in even the most simple of systems and arises from interactions among the agents within the system over time ${ }^{12 .}$ Within an intermodal transport system both types of complexity will be seen, however the initial simplified model will have reduced combinatorial complexity due to its reduced size.

System dynamics can be considered as an iterative approach to modeling, which broadly follows five stages:

1. Articulating the problem that needs to be considered

2. Developing a theory or "Dynamic Hypothesis" about the causes of the problem

3. Formulating a simulation model to test the dynamic hypothesis

4. Testing and validating the model

5. Designing and evaluating policies for improvement

Within this investigation, the aim is to demonstrate the first 4 stages of this procedure and to suggest methods of future model development in order to fulfill this framework by the end of the project. Often after a model is tested it is noted that certain changes to the model will be required and therefore iterations between any two stages can occur as many times as is necessary to formulate a suitable and reliable model.

Many different tools are available for use by system dynamicists, the most common tools used are causal loop diagrams and stocks and flows diagrams. Mathematically, the basic structure of a formal system dynamics computer simulation model is a system of coupled, non-linear, first-order differential (or integral) equations of the form:

$$
\frac{d}{d t} x(t)=f(x, p)
$$

Where $\mathrm{x}$ is a vector of levels, $\mathrm{p}$ is a set of parameters and $\mathrm{f}$ is a non-linear vector-values function. ${ }^{13}$

\section{B. Impact Analysis as proposed by Davies et al., $, 11,14,15$}

An impact can be defined as a "measure of how a system element deviates from a "normal" operational mode due to a change in the operation of another element existing within the same architecture, or due to an interaction with an external environmental condition. ${ }^{1}$ This means that if a disturbance or influence acts on a system which is running in a pre-determined "normal" mode, the impact is the value from which the system deviates. The advantages of introducing impact into a system dynamics model is that impacts can "qualitatively determine the elements in the system that would be affected by a modification.' 1

Impact analysis is the technique in which the effects of impact are investigated, simulated and then concluded. The technique shows the influences that individual elements have on the whole system architecture. The function of an impact analysis is to:

- 'Identify element relationships and interdependencies'

- 'Analyze the impact of one element on any or all of the elements within the system architecture.' 11 
For use in this work, an impact variable will be included for each of the transport systems being analyzed since a singular event may have differing effects on each system. This value for impact must be a dimensionless, user defined quantity that will enable specific events to be considered, since some events such as the Icelandic Volcano will have a much more significant effect to one specific transport system, whilst other events such as an earthquake will have large scale effects throughout the entire transport network. Although impact analysis is a qualitative approach, the user can define the model in order to give quantitative measures that can be used to influence the computational process. This will enable thorough definition of a number of scenarios.

\section{Modeling Approach}

The purpose of this investigation is to demonstrate the use of system dynamics as a tool that can predict the movement of passengers during times of disturbance. This will incorporate elements of impact analysis within a system dynamics model. The aim of the model is to demonstrate the different effects on a system depending on varying lengths and severity of impact, ensuring that the model can be used to predict almost any scenario. In order to achieve this, a multi-modal transport system has been designed using the system dynamics software called VenSim PLE ${ }^{16}$.

This program enables different views of the same model to interact, which facilitates transfers between multiple transport systems to be modelled. The program uses stocks and flows alongside causal loops to develop a model in which the complex interrelationships between the systems can be thoroughly defined. As such it is possible to incorporate an impact model, whose effects can propagate through the entire transport system according to user defined variables.

Impact will be qualitatively defined on a scale similar to that used in previous work by Davies et al., $2010{ }^{14}$ as shown in Fig. 1. The impact on each system will be measured on a scale of zero to one, with one meaning complete system failure and zero for no impact on the system. Furthermore, the user will be able to modify the model in order to thoroughly define the boundaries between the impact levels. However, for simplification reasons the nominal impact or "Noise" has been replaced for this study as "Negligible Impact," which means when an impact is below a user defined boundary the effects on the system can be ignored.

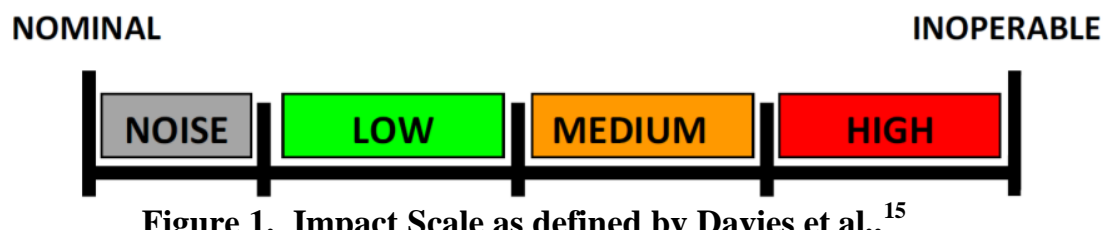

Figure 1. Impact Scale as defined by Davies et al., ${ }^{15}$

\section{Multi-modal Transport Model}

In order to investigate the effect of impact on the movement of passengers around a dual-modal transport system it was necessary to design and construct a system dynamics model. This model incorporated two transport systems which were intrinsically linked through flows of passengers. Through analysis of the system's functionality conclusions can be drawn as to whether the technique is suitable for use commercially within the industry. At this stage of the project a basic, simplified model has been constructed to demonstrate the behaviour of an intermodal transport system and to demonstrate the capability of the system to generate results similar to those seen in real data.

The model itself consists of four sectors:

- Two Transport system models- Demonstrating the relationships between demand for travel and actual number of passengers entering the system.

- One Transfer model- Demonstrating the relationships between the two transport systems and the levels of passengers transferring between the two

- One Impact model - Within which users can thoroughly define an impact and its effects on four flows within the other sectors: entrance rates, exit rates, demand rates, and transfer rates 


\section{A. Transport System Models}

The most important model for use in this project was the two transport systems and generating suitable feedback loops to sensibly model the relationship between travel demand and passengers entering the system. It was necessary to develop a model, which would have a balancing nature to return to a "normal" operational mode. A large assumption made for this model was that yearly variation was ignored. This is suitable for this investigation as the model is focused on the variation in passenger numbers caused by a disturbance within the system rather than the natural variation.

In order to design this model two stocks were inserted to model the "Demand for Travel" and the "Passengers in the System," as can be seen in Fig. 2. The passengers within the transport system have been aggregated to a single stock, but in future iterations of the model this stock can be broken down to show the movements of passengers within the system. The equations used to calculate the size of the stocks are of the form of Eqn. 2, a simple integration calculation.

$$
\begin{aligned}
& \text { Demand for Travel } \\
& \qquad=\int\left(\text { Demand Increase - Satisfied Demand - NonTravel Rate, Demand for travel } t_{t_{0}}\right)
\end{aligned}
$$

When calculating the flows it was important to ensure the demand flow would not go negative even when a disturbance is acting on the system. To do this, a variable 'Effect' is included, which relates to how the impact influences the flow. These will be discussed further within the Impact Models section. As such:

$$
\text { Demand Increase }=\operatorname{MAX}(0, \text { Desired Demand Increase }+ \text { Demand Effect })
$$

A major difference between 'Demand for Travel' and 'Passengers in system' stocks is that one flow shows information, whilst the other is a physical flow of passengers. This results in two separate stocks and flows systems being used and also means that a period of time will be required for passengers to transfer their demand into action. It is assumed in the model that passengers are from an infinite stock, when in reality economic limitations will prevent a number of potential passengers from travelling. For the purposes of this investigation the average time to enter system has been used for simplification and the entrance rate flow and exit rate flow can be given as:

$$
\text { Entrance Rate }=\text { Demand for Travel/Average Time to Enter System }
$$

$$
\begin{gathered}
\text { Exit Rate }=\operatorname{MAX}(0,((\text { Passengers in System }- \text { Passengers Transferring }) \\
+ \text { Exit Effect }) / \text { Average Duration of Journey })
\end{gathered}
$$

It is noticeable that the exit flow also requires a MAX function, whilst the entrance rate does not. This is because the flow of information is prevented from going negative by the MAX function in the demand increase. Another noticeable feature of this model is that the exit rate is clearly intrinsically linked to both the other sectors, with 'Effect' and 'Passengers transferring' variables both affecting the flow.

Further assumptions made for the model are that the 'demand increase' will equal the 'desired demand increase', but will be constrained to be nonnegative. This is due to the market for potential travellers not being modelled. Also, for this model the expected time for passengers to enter the system has been assumed to be the same as the average time to enter the system. In reality this will fluctuate with the economy and passenger opinion. These considerations can be made in future iterations of the design. 


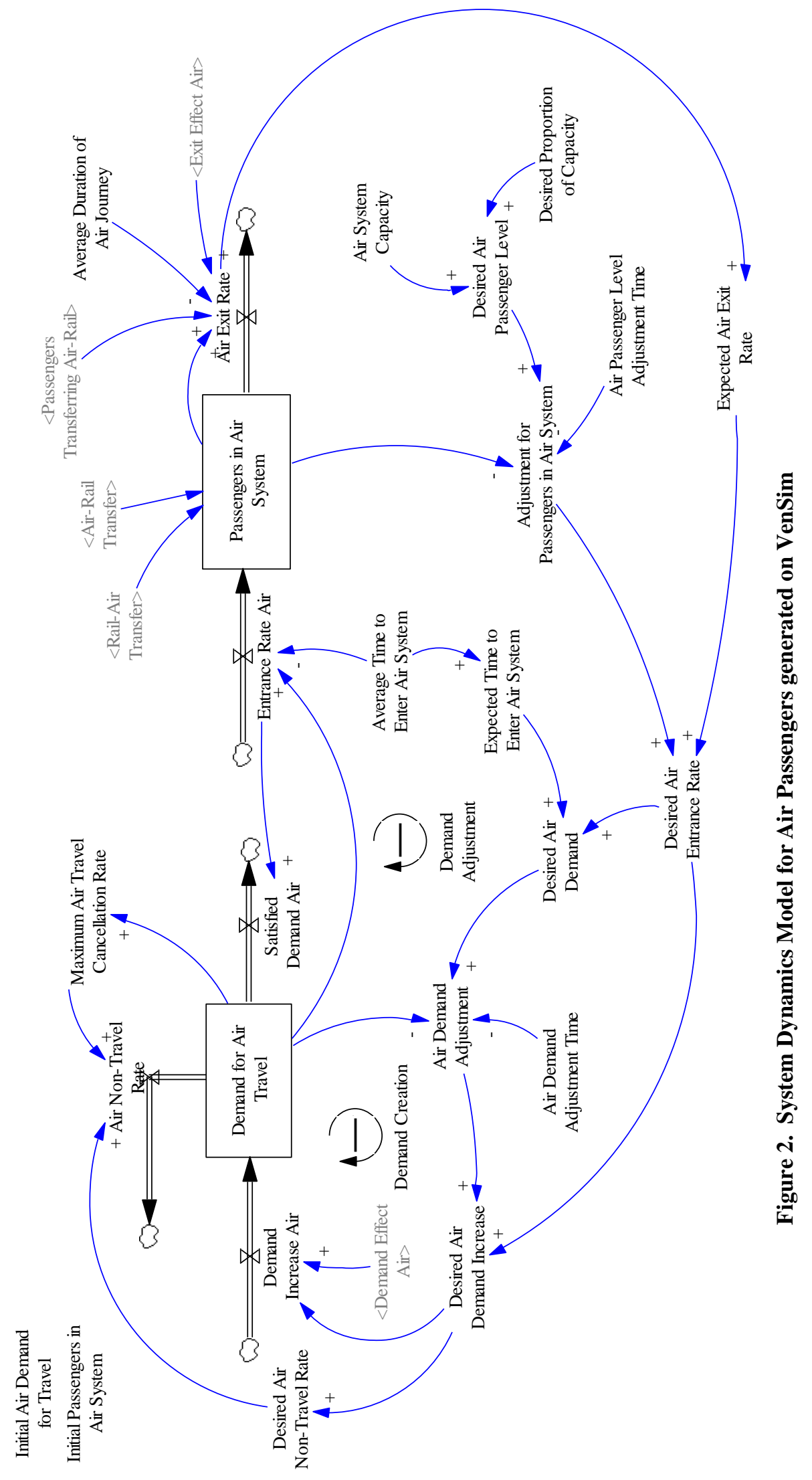




\section{B. Transfer Model}

In order to see the effect an impact has on system transfers, a model had to be generated to enable passengers to transfer from the rail system to the air system and vice versa. The proportions of these will depend on the system and the impact level seen within the system. The systems are modelled with one flow for the Rail-Air Transfer and the other for Air-Rail Transfer, enabling the flows to adjust depending on the impact, as can be seen in Fig. 3. This also enables users to define a transfer ratio, which they feel is best suited to the system being investigated.

For this investigation, user assumption and judgement has been used to model the transfer proportions due to a lack of real life data within this area. A trial and error method was used until the model clearly demonstrated the change in passenger numbers after a disturbance is introduced based on the data calculations in the methodology section. With further research, this relationship can be more accurately defined and produce predictions on passenger numbers in order for transport industries to appropriately prepare for potential impacts on the system.

The transfer rates are obviously limited by a capacity, either due to the intermediate transport facility or limited by the transport system itself. As a result, not all passengers desiring to transfer from one system to another will be able to exit the system in this way. In order to model this, the 'Transfer' flow is given as:

$$
\text { Transfer }=\text { MIN(Desired Transfer Rate, Maximum Transfer Rate) }
$$

Where the 'Maximum Transfer Rate' is a user defined constant and the 'Desired Transfer Rate' is a user defined function of passengers within a system as given in Eqn. 7.

$$
\text { Desired Transfer Rate }=\frac{((\text { Passengers in System } \times \% \text { Transfer })+\text { Transfer Demand Effect })}{\text { Time Taken for Transfer }}
$$

A drawback to this modeling technique is that the transfers are not based on the passenger levels in the receiving system, therefore may cause overcrowding. However for this investigation, this can be prevented through suitable user inputs and correct modelling of impacts. For a more robust model this issue would have to be addressed.

\section{Impact Models}

Within VenSim impact could be modelled in a number of different ways, however for the purposes of this investigation impact has been modelled as a 'Pulse' function, with separate user defined variables that control the magnitude of the impact, length of time the impact acts on the system and the time at which the impact starts. As such the equation for impact can be given by:

$$
\text { Impact }=\text { Magnitude of Impact } \times \text { PULSE(Impact Start }, \text { Impact Duration })
$$

When considering implementing impact to the model it was necessary to identify which variables would be affected by the impact and which would not. As the focus of the investigation is on the flows and how their rates change dependant on impact levels, three variables were identified that would change during a disturbance:

- Demand Rates

- Exit Rates

- Transfer Rates 


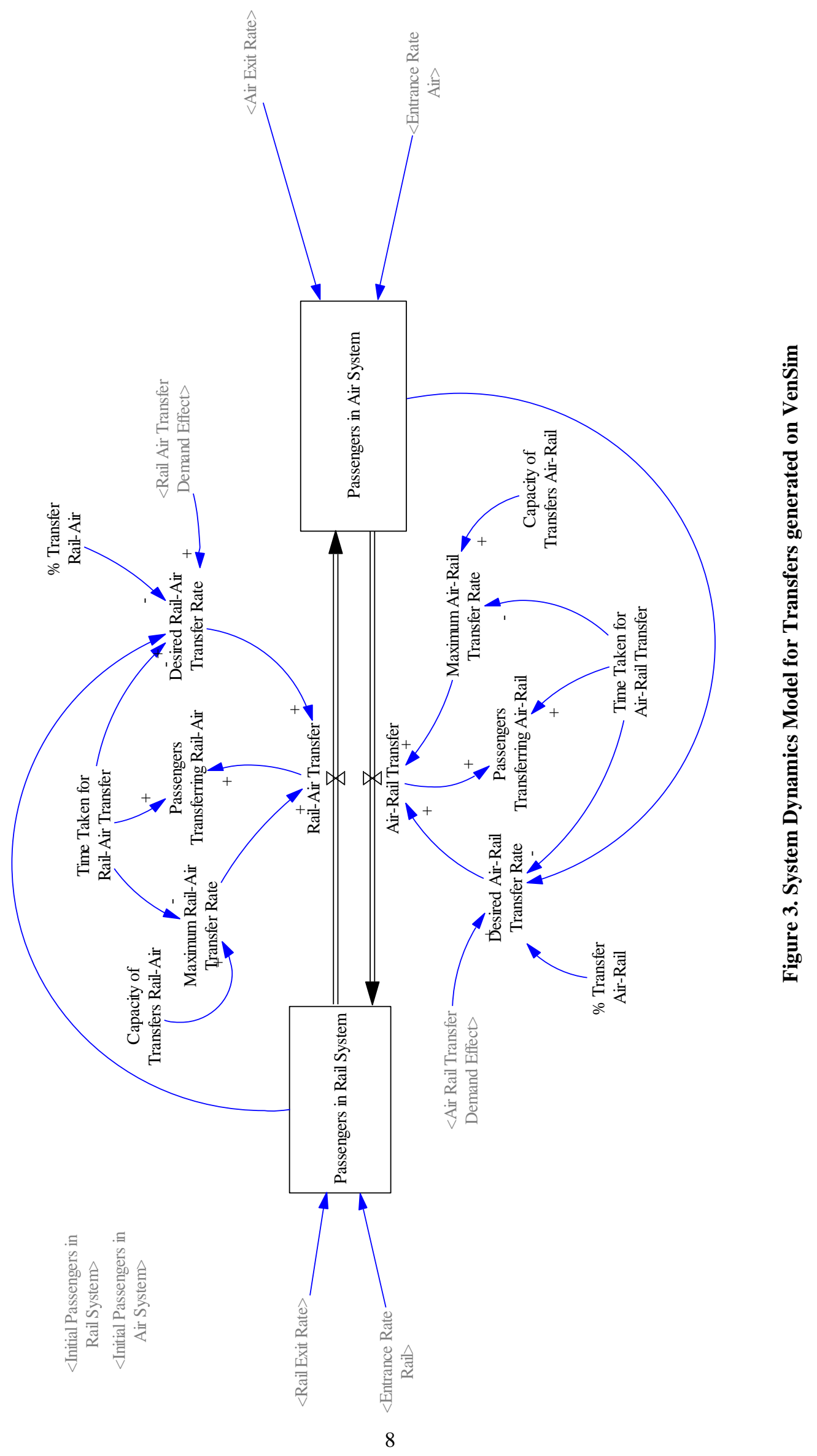

American Institute of Aeronautics and Astronautics 
As a result, suitable impact models had to be generated in order to manipulate the standard impact scale (0-1) into qualitative data for use within the system. Since there two different transport systems were modeled, six impact models were required to dully define the impact's affect on the system. Furthermore, the size of the impact had to respond to both the severity of the disturbance and the length of time the disturbance acts on the system. As a result is was necessary to develop another stock and flow diagram, which would enable the impact's effect on the system to increase up to a user defined maximum and then recover once the impact was removed. A basic structure showing the build up of impact effect on the entrance rate can be seen in Fig. 4, within which 'ExA' stands for 'Exit Air.'

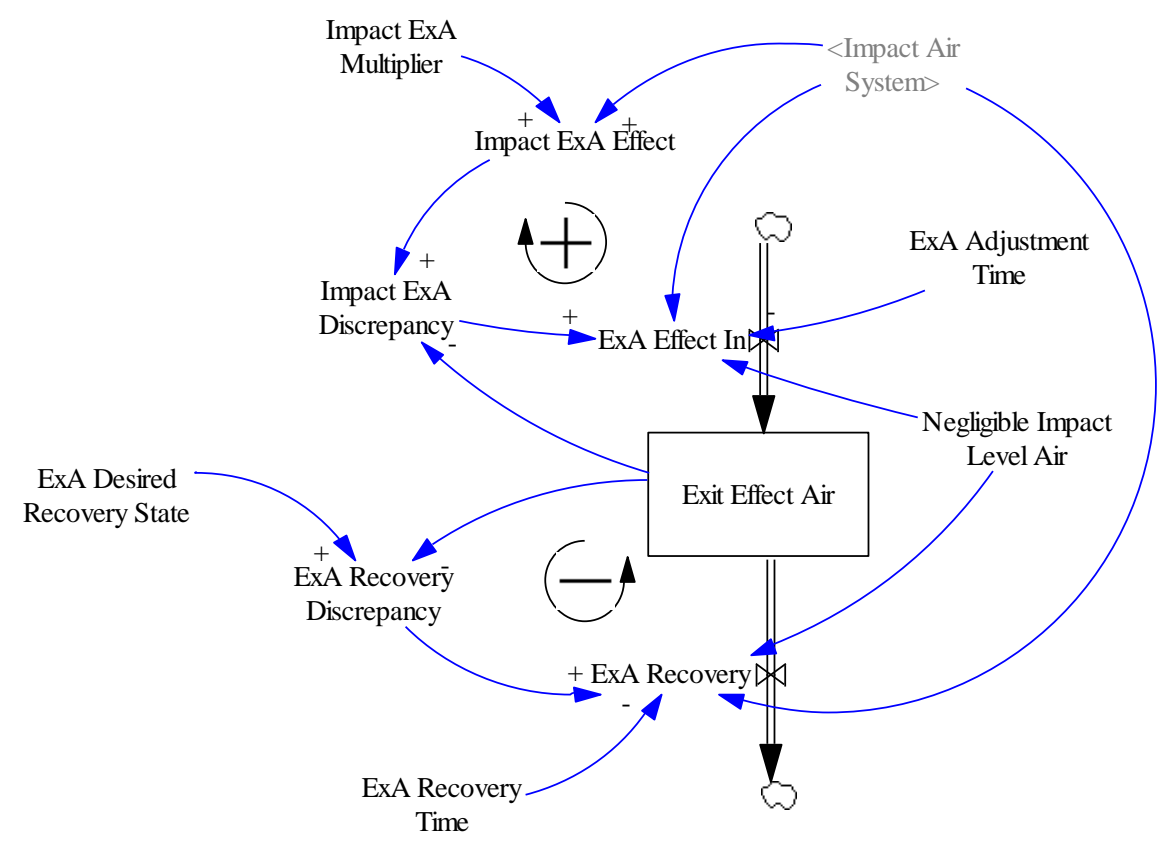

Figure 4. Impact Model to show build up of Effect generated on VenSim

From the basic impact generated by the shadow variable in Fig. 4 and given by Eqn. 8 the impact multiplier will manipulate the value into a maximum suitable qualitative number that can be used in the other sectors of the model. The reinforcing loop seen above will cause the stock to increase up to the value calculated within the 'Impact Effect' variable. The rate at which the build up occurs depends on the 'Adjustment Time,' and a 'Negligible Impact Level' is included such that a user defined low level of impact can be ignored. As such the equation for 'Effect In' is:

$$
\begin{aligned}
& \text { Effect In = IF THEN ELSE (Impact } \\
& \qquad \text { Negligible Impact Level, Impact Discrepancy/Impact Adjustment Time, } 0)
\end{aligned}
$$

This states that when an impact is greater than the negligible allowance the disturbances effect on the system increases, however once the impact becomes below this allowance no further disturbance will be caused. In a similar way, once the negligible impact has subsided the system can start recovering. For the purposes of this investigation the negligible impact level will remain equal for both entrance and exit effects, as can be seen in Eqn. 10.

$$
\begin{aligned}
\text { Effect Out }= & \text { IF THEN ELSE }(\text { Impact } \\
& >\text { Negligible Impact Level, } 0,- \text { Recovery Discrepancy } / \text { Recovery Time })
\end{aligned}
$$


Although this technique uses the 'If Then Else,' function, which is computationally expensive, it is the most suitable method for this investigation. Furthermore the model for this investigation is small therefore the effect of the functions use is unnoticeable.

The variable 'Recovery' will aim to return the flow back to the normal operation, as defined by the user through the 'Desired Recovery state' variable before a simulation occurs. Within Fig. 4, the desired recovery state will be set to 0 for each impact effect in order for the flows elsewhere in the model to have no effect once the disturbance is over.

\section{Methodology}

The purpose of this study is to analyze the suitability of system dynamics to perform an impact analysis of a multi-modal transport system, through the use of computer simulated models. This impact analysis will be used to demonstrate the rigidity of the transport system by demonstrating the large levels of passenger movement caused by certain levels of disturbance. This will be performed by analyzing the movement of passengers into and between different transport systems under normal conditions and during times of disturbance. The passenger levels will be modelled as stocks and movement around the system will be modelled as flows. Demand for travel will be modelled in a similar way; however whilst modelling it is important to note the difference between physical flows and information flows and the varying limitations of each.

This study introduces the concept through analysis of a simplified, two-mode transport system within the UK. The modes analyzed in this work will be the rail and air systems, which will be modelled on a monthly basis. Despite this the system could be modelled on any time scale, from hours to years, as the user controls the impact effects. Using monthly data will show less extreme trends due to the hierarchical nature of impact. For the purposes of this investigation, a monthly time scale is suitable as it can clearly show the desired trends and is easily comparable with collected research data.

The system will be inclusive, therefore only passenger numbers travelling within the system will be considered. This requires the system in question to be thoroughly defined by the user. In order to verify that the model can produce a sensible output, a simulation will be conducted based on the domestic UK transport system during the disturbance caused by the Icelandic volcanic eruption in 2010. Therefore, the transport system in question had to be thoroughly defined before simulations could occur.

Information obtained from the UK Civil Airport Authority $(\mathrm{CAA})^{17}$ provides accurate data on the number of passengers travelling domestically. A passenger entering the air system for this investigation can be defined as: Any passengers travelling (or intending to travel) on a UK domestic flight to an airport regulated by the CAA which has a minimum of 500,000 domestic passengers per annum. This criteria means there are 21 airports within the system as shown in Table 1. Using further statistics provided by the $\mathrm{CAA}^{18}$ data for all passengers travelling within the system could be calculated for the period between 2008 and 2010. Passenger numbers for an average month can be calculated by neglecting all anomalous data, caused by well known aviation disturbances. The average monthly passenger level for the 33 normal operating months in question was $1,601,275$.

Modelling the annual variation would increase the models complexity and is unnecessary at this stage of the investigation. The real life trend in the passenger data can be seen within the results section.

Table 1. The 21 Airports included in the Air System

\begin{tabular}{|c|c|c|}
\hline Airport Name & Airport Code & $\begin{array}{l}\text { Annual Domestic } \\
\text { Passengers }\end{array}$ \\
\hline HEATHROW & LHR & 4840832 \\
\hline EDINBURGH & EDI & 4431517 \\
\hline GATWICK & LGW & 3496378 \\
\hline GLASGOW & GLA & 3443040 \\
\hline $\begin{array}{l}\text { BELFAST CITY } \\
\text { (GEORGE BEST) }\end{array}$ & BHD & 2677455 \\
\hline $\begin{array}{l}\text { BELFAST } \\
\text { INTERNATIONAL }\end{array}$ & BFS & 2389704 \\
\hline MANCHESTER & MAN & 2237593 \\
\hline STANSTED & STN & 1723067 \\
\hline ABERDEEN & $\mathrm{ABZ}$ & 1603549 \\
\hline JERSEY & JER & 1356296 \\
\hline NEWCASTLE & $\mathrm{NCL}$ & 1249731 \\
\hline BIRMINGHAM & $\mathrm{BHX}$ & 1130227 \\
\hline BRISTOL & BRS & 1079148 \\
\hline SOUTHAMPTON & $\mathrm{SOU}$ & 1064703 \\
\hline LUTON & LTN & 937452 \\
\hline GUERNSEY & GCI & 864738 \\
\hline $\begin{array}{l}\text { LIVERPOOL (JOHN } \\
\text { LENNON) }\end{array}$ & LPL & 804879 \\
\hline ISLE OF MAN & IOM & 635894 \\
\hline $\begin{array}{l}\text { EAST MIDLANDS } \\
\text { INTERNATIONAL }\end{array}$ & $\overline{E M A}$ & 578085 \\
\hline LONDON CITY & LCY & 556188 \\
\hline INVERNESS & INV & 518451 \\
\hline
\end{tabular}

When researching data for the rail system it was

10

American Institute of Aeronautics and Astronautics 
important to select suitable, comparable data for the system. As such, it was necessary to exclude every small rail journey in the UK. Based on passenger data from the Office of Rail Regulation (ORR) ${ }^{19}$ passengers within the rail system could be defined as: Any passenger travelling between Government Office Regions (GORs), i.e. a journey that could be made by train or comparable public transport, rather than short commutes. From the collected data, which was given annually, it was found that 370.03 million journeys were made between GORs ${ }^{18}$. Therefore, averaging this over a 12 month period, it can be assumed that 30,835,800 passenger journeys are made monthly within the defined UK rail system.

Using this input data for the model, without impact being applied, the systems will show the average monthly passenger numbers. Since the disruption to the systems lasted approximately two months, the disruption duration for this simulation will also be two months, with an impact level of 0.7 on the air system. This impact level has been selected as, despite widespread closure, there were still a number of internal flights completing journeys when the atmospheric conditions permitted. A more significant impact, with all flights grounded for an entire timestep (one month in this case) would have warranted an impact level of 1. Furthermore, as the volcanic ash cloud also influenced the passengers within the rail system the impact level for rail system will be set at 0.2. In order to demonstrate the difference between normal operation and the effects caused by the disturbance, the simulation will run for a period of 2 years ( 24 months) with the impact occurring on the 15th month. This will represent an average of the time period between January 2009 and December 2010.

From this, the time variables and impact variables will be manipulated using the function SyntheSim ${ }^{14}$ in order to give the impact variation as seen in the real life data based around the Eyjafjallajökull volcanic eruption. The results of the simulation will then be compared to the collected data from which conclusions can be drawn on the suitability of the use of system dynamics to model accurate simulation of disturbances on a transport system. Assumptions have been made throughout the modelling procedure that will be outlined in the next section of the report.

Once this test is completed a number of further tests can be performed on the model to demonstrate its use as a predictive tool. These will investigate the effect on the system if different levels and durations of impact occur on the system. In order to complete the tests the model will be modified as outlined below:

- As the model will have been calibrated with a recent event, the 'impact multiplier' and 'adjustment time' variables will remain at the same values discovered by the previous test

- The effects of impact will be analyzed by comparing the results from the Icelandic volcano test with a number of other impact magnitude combinations

- The effects of impact duration will also be investigated through modifying the 'Impact duration' variable.

These tests will demonstrate the systems behavior under a number of different scenarios, suggesting its possible use as a predictive tool.

Once these simulations are complete, future considerations can be made and suggestions can be given on methods of developing the model further to generate an accurate predictive tool for use within the industry. This will include methods of expanding the model to include more transport modes and to include hierarchical impact, by developing sub-system models to show the movement of passengers within the transport sector. By completing accurate simulations on a larger scale it becomes more plausible to consider sub-system passenger movements.

\section{Results \& Discussion}

The previous section outlined how this investigation used the designed system dynamics model to demonstrate the movement of passengers around a dual-modal transport system. Using data regarding passenger movements in the UK transport system ${ }^{17}$ monthly passenger data for the air transport system has been plotted. The primary trend in Fig. 5 shows an annual variation with passenger numbers increasing during the summer months and reducing in the winter. From this variation there is a clear anomalous trend around April and May 2010, which is caused by the effects of the Icelandic volcano, demonstrating the rigidity evident within the system. This variation will be used to calibrate the model for the defined system. Similar methods have been used for the rail system. 


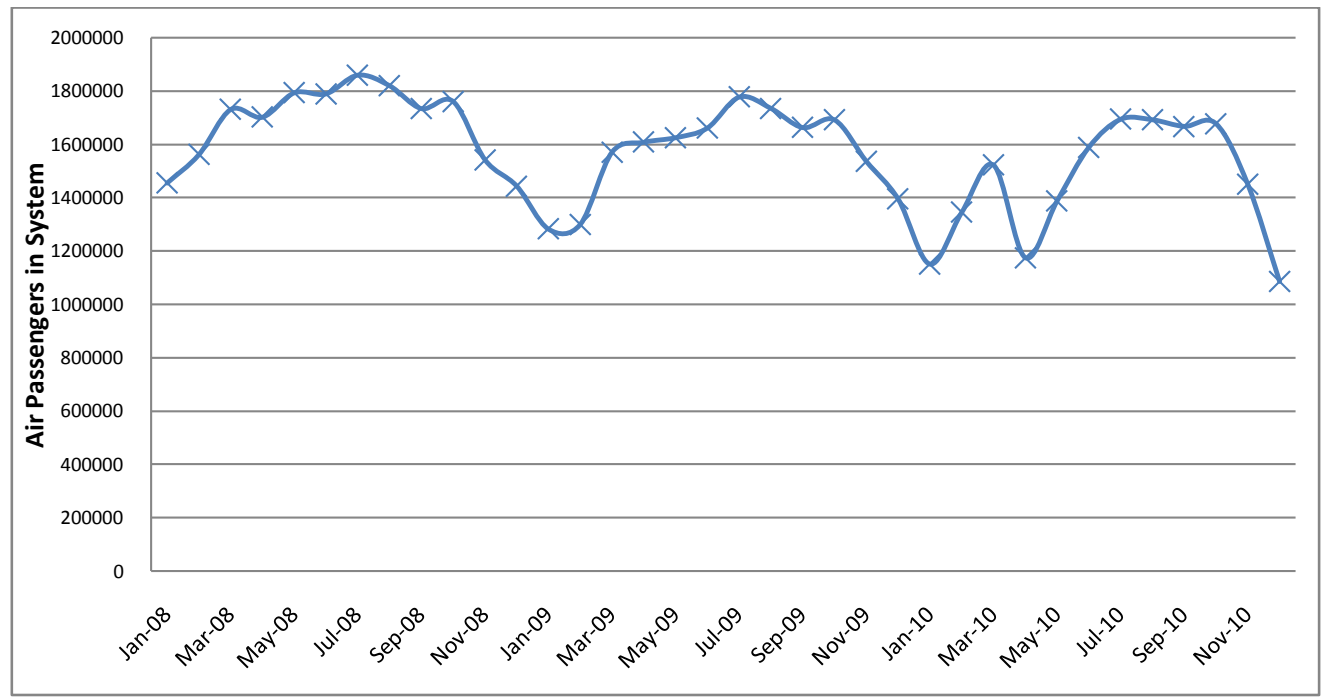

Figure 5. Air System data for the defined UK Transport System

\section{A. Model Comparison with Passenger Data}

A simulation was conducted for a two year period with a disturbance affecting the simulation on the $15^{\text {th }}$ month, i.e. April 2010. The reason for having a two-year simulation was to demonstrate the difference between normal operation and the disrupted impact. Data points were saved every 0.25 timesteps to ensure the simulation produced a smooth trendline.

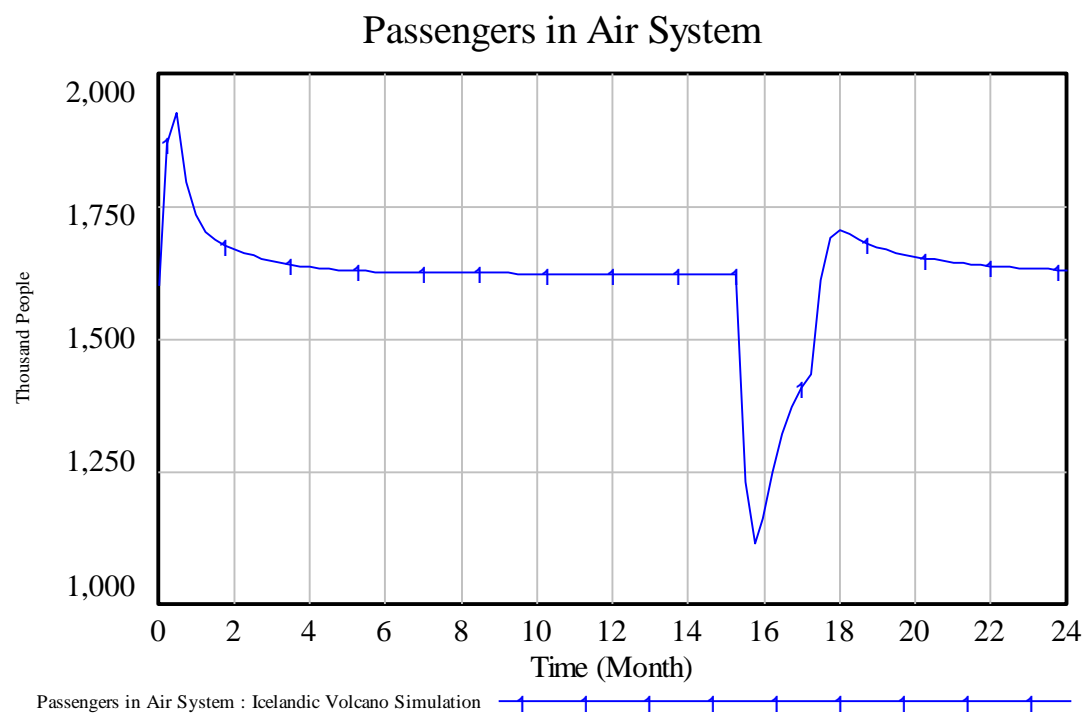

Figure 6. Air System data for the simulated UK Transport System after Icelandic Volcano Impact

Figure 6 shows a similar variation to that shown in Fig. 5 with the number of passengers within the air system falling to $1,115,230$ passengers by the end of the $15^{\text {th }}$ month, April 2010. Furthermore, it can be clearly seen that the system naturally recovers at a similar rate to that seen in the researched data, taking approximately 3 months to return back to the 'normal' levels. This demonstrates that the system dynamics model can produce data trends similar to those seen in real life, and responds in a similar way to the real data trends.

12

American Institute of Aeronautics and Astronautics 
Further simulated demonstrate how the impact affects the rail system, as can be seen in Fig. 6.

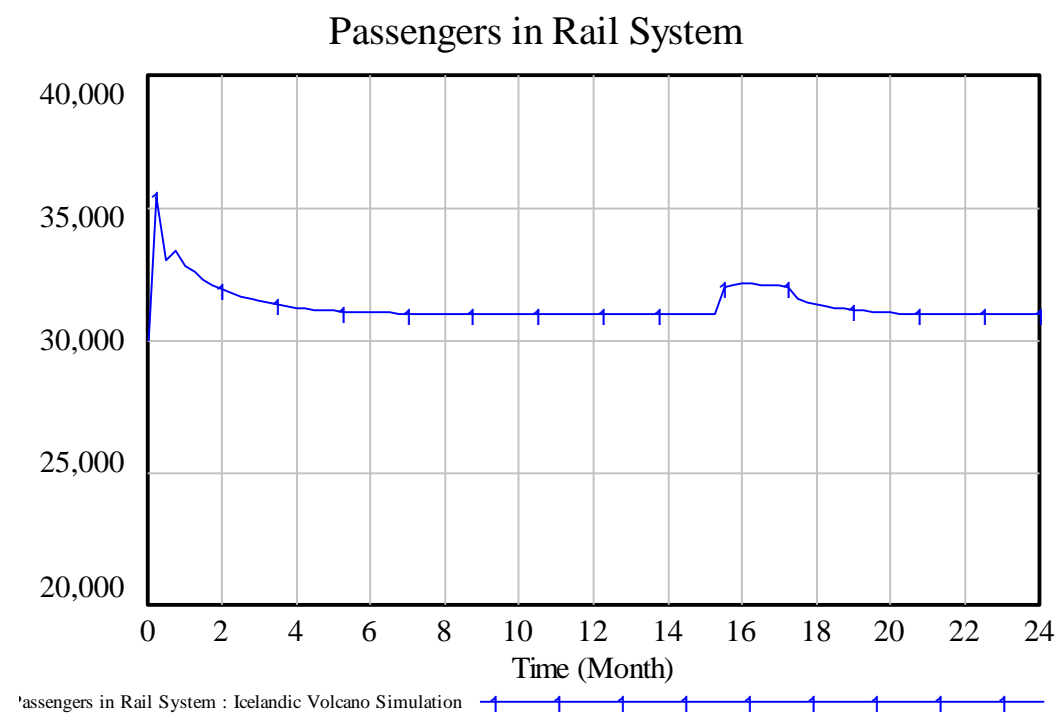

Figure 7. Rail System data for the simulated UK Transport System after Icelandic Volcano Impact

In comparison to Fig. 6 it can be seen that the rail system contained significantly more passengers than the air system, and that the impact caused a greater demand on the rail system, rather than having a negative effect. Further to this, the impact disturbed the rail system for a more prolonged period of time than the air system. This may have been because of passengers' fears that the volcano may erupt again and cause further disruption.

Within both Figs. 5 and 6 it can be seen that the normal passenger level takes around 6 timesteps to settle on the user defined value. This is due to the modelling feedback procedure used and it must be noted that no impacts should be implemented before this variation settles.

Figure 8 shows the variation for a transfer between the two transport systems:

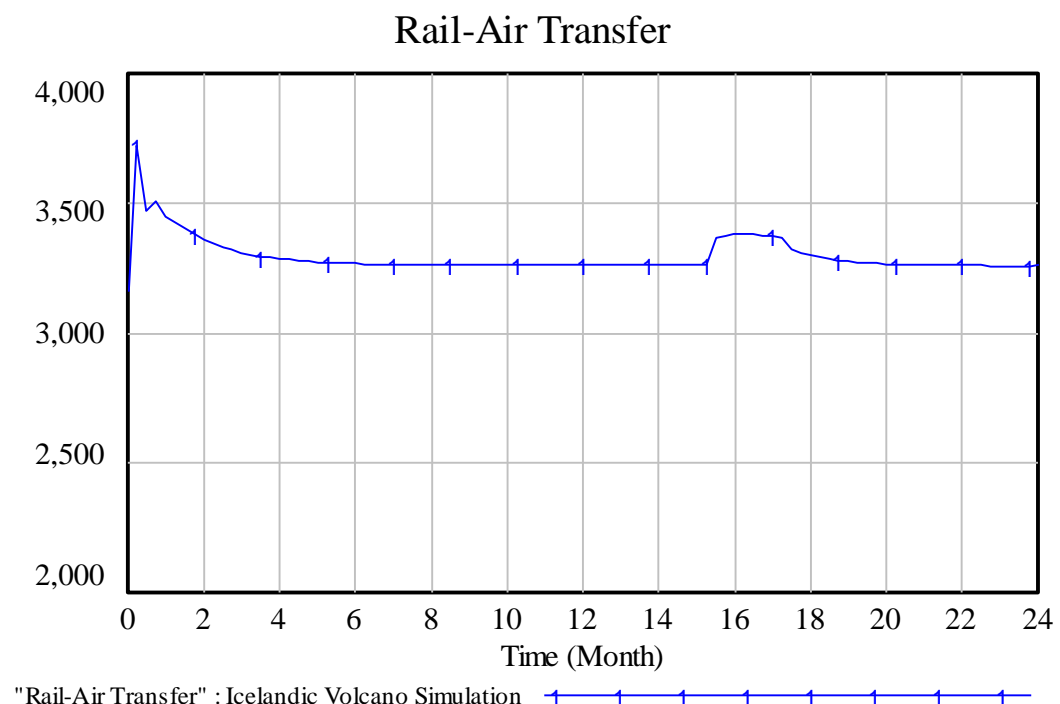

Figure 8. Transfer Rail-Air rate for the simulated UK Transport System after Icelandic Volcano Impact

This figure shows how the impact affects a system transfer and causes a secondary effect on the system, that the levels of passengers transferring to the air system will increase caused as a result of the increased levels of 
passengers within the rail system. As the maximum transfer rate is not exceeded the variation continues as normal, however it is important to note that the assumption of the transfer level being proportional to the level of passengers within the system has a much more significant effect on the transfer rate than the 'transfer effect.' This variation appears to suggest that more passengers enter the air system to help recover the levels of passengers, however in reality this transfer rate will decrease after an impact. As a result this model will need further iterations in order to make this variation more realistic. This demonstrates that, while the model shows the correct levels of passengers within the stocks, the flows within the system need further improvement to demonstrate actual passenger movement.

\section{B. Magnitude of Impact}

To demonstrate how the model can be used as a predictive tool, hypothetical scenarios based on varying levels and durations of impact will be simulated. This will give an estimate for the levels of passengers within the air and rail systems for the defined UK transport system. In order to determine the reliability of these estimates, comparisons must be conducted between the simulated results and real life data collected for disturbances of a similar impact level. This will be discussed further in the following section.

To investigate the effects of impact magnitude, the model will be run with a number of different impact combinations. This will demonstrate the different effects between large impacts within the air or rail systems and demonstrate how larger impacts will have a notably more significant effect. To analyze, comparisons for the levels of air passengers will be demonstrated, impact ratios selected are combinations of a low (0.1), medium (0.4) and high (0.8) levels of impact. The disturbance will continue to last 2 months and was programmed to occur on the system on the $7^{\text {th }}$ timestep.

\section{Passengers in Air System}

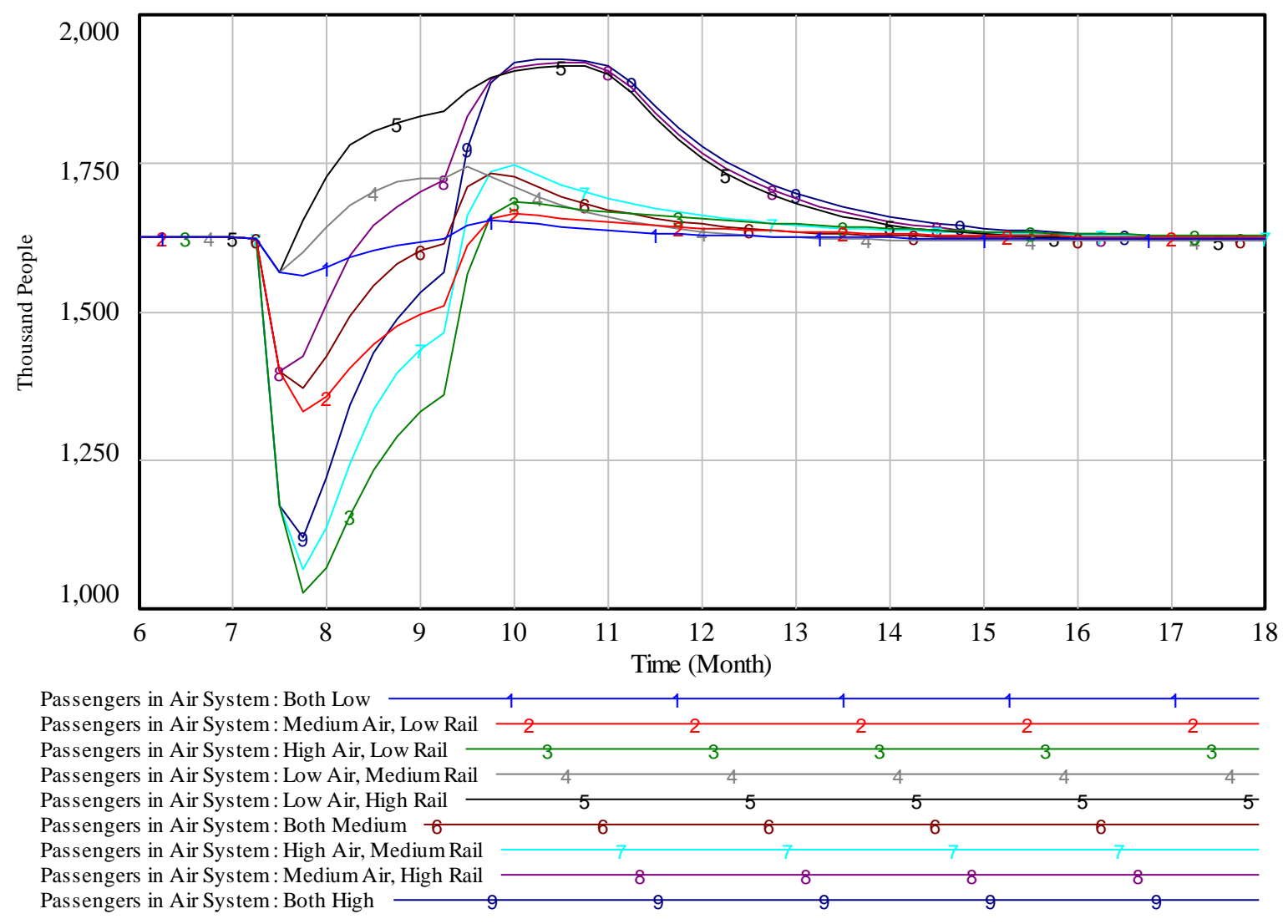

Figure 9. Passenger Levels within the Air System for different Impact Ratios 
Figure 9 shows that when both impacts are low, there is only a minor deviation in the level of impact. When the impact level within the rail system is higher than that of the air system, a clear increase in the level of passenger numbers over the following months can be seen, this deviation takes longer to recover than that of the air system, suggesting that the necessity for air travel is greater than that for rail, arguably down to length of journey times.

An interesting trend can be seen within trends 3, 7 and 9, showing that the levels of air passengers will decrease at a reduced level if the impact is widespread among the systems. Therefore if the rail system also has large levels of impact, some passengers will remain within the air system regardless. Further modelling would demonstrate that this is unrealistic since in reality, passengers would choose an alternative form of transport, such as automobiles or ferries. This graph also suggests that the reason for the slight increase in passenger levels once the disturbance disappears is due to the lagging recovery of the rail system. Through further research and modelling iterations this trend can be accurately modelled.

Simulation 5 also more clearly shows the desired trend in passenger levels immediately after the disturbance, with a slight initial decrease in passengers, followed by a quick recover and then receiving the excess demand from elsewhere in the transport system.

\section{Duration of Impact}

In order to demonstrate the model's response to different levels of impact a further test was performed using the same impact ratio as given by the Icelandic volcano test. This disturbance acted on the system for a period of 2, 5, 8 and 11 months, which could represent the effects on the system had the volcano continued erupting at the same intensity for a prolonged period of time. For analysis purposes the impact again started on the $7^{\text {th }}$ timestep.

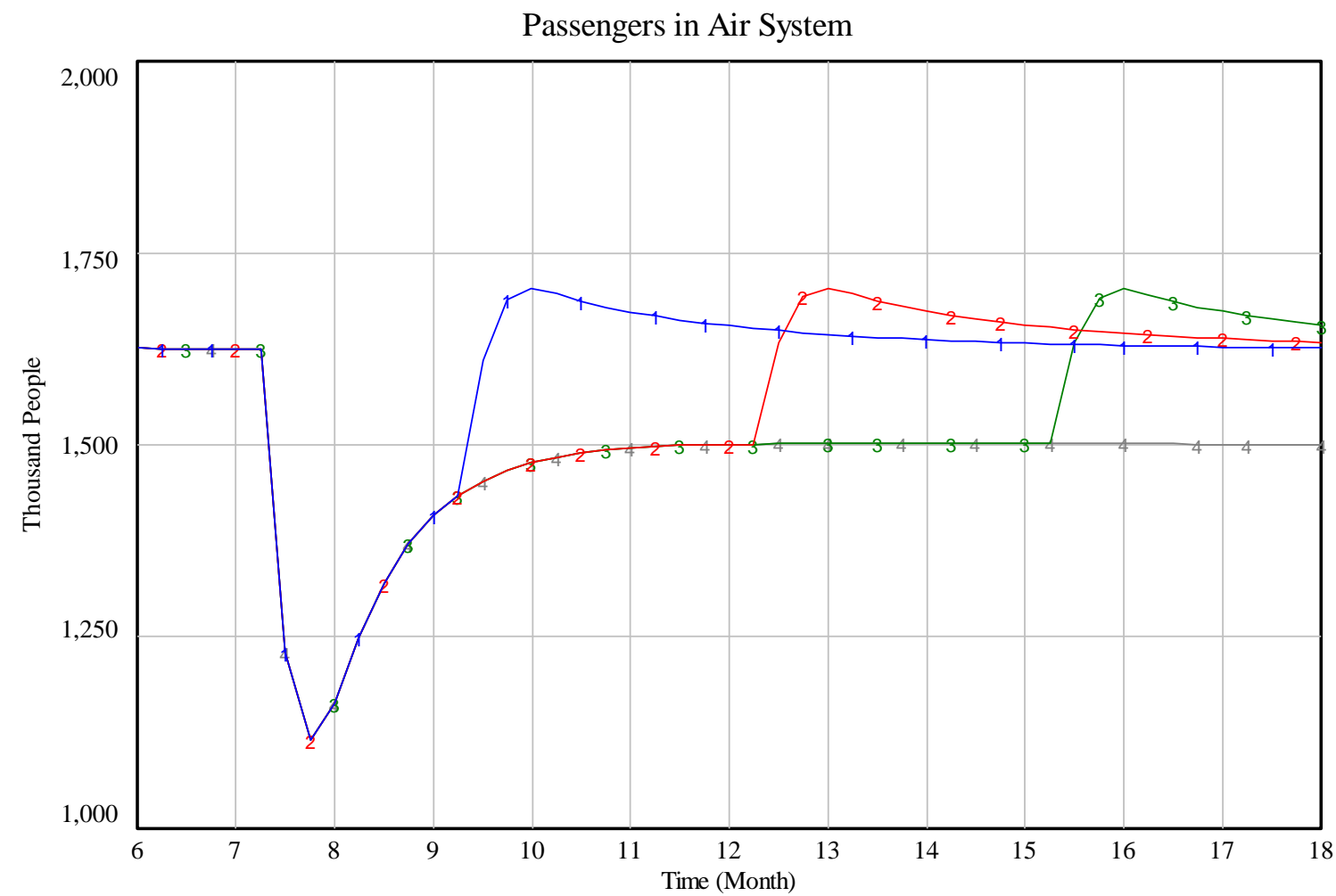

Passengers in Air System : 2 Months

Passengers in Air System : 5 Months

Passengers in Air System : 8 Months

Passengers in Air System : 11 Months

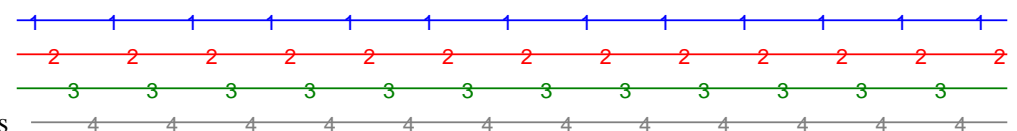

Figure 10. Passenger Levels within the Air System for different Impact Duration 
As can be seen in Fig. 10, the system responds naturally to cope with the disturbance generated on the system, enabling the numbers of passengers to enter the system, despite relatively high levels of impact. Impact was generated on the system as a step input lasting a determined duration on the system. The system, as programmed according to the Icelandic volcanic eruption data, then produced a natural response in the form of a decaying curve, as a result lengthier disturbances produced similar responses. From this distribution it can be seen that according to the system definitions used for the initial test the system can recover to a level of 1.5 million passengers a month. This suggests that the UK transport system could cope with a demand of this scale over a longer period of time. This conclusion is based on the assumption that the relationships between the variables for the initial test were correct. In order to investigate the accuracy of the model, it must be tested against, and calibrated with a number of different real life system disturbances.

This model also suggests that the current method of modelling impact is unsuitable for uses on this investigation. Figure 10 shows an immediate increase in passenger levels once the impact is completely removed, when in reality the impact would decay slowly over a period of time. For future iterations of the model, the impact will have to be modelled alternatively. An exponential decay function, could be one alternative to the current modelling method.

\section{Conclusion \& Future Work}

The study demonstrates the potential application of system dynamics for use on complex multi-modal transport systems and highlights key areas for further research. The results produced and trends noted suggest that a number of improvements and further considerations are required in order to progress the project further. The key observations from this study can be summarized:

- A simple system dynamics simulation model can be used to produce variations in passenger level similar to those seen in real transport systems.

- These variations demonstrate the rigidity of the transport system due to the complex interrelationships created between the individual systems.

- The model can easily be modified (with subsequent research) to model any transport system. It can also be suggested that a similar methodology can be used to perform simulations with a different timestep

- The system dynamics model generated will require significant further investigation and development in order to produce accurate results, which will include development of further transport systems

- A more detailed model to demonstrate the degradation of impact is required for more accurate studies.

From this investigation it can be seen that a system dynamics feedback model can be used to show the balancing feedback nature of complex intermodal transport systems. Considering the model is significantly simplified the variation produced is comparable to that of the real life data. The model clearly shows a variance in passenger levels within the systems as a result of a disturbance, which responds in a suitable manner dependent on impact magnitude and duration. Despite this there are few limitations that must be identified.

Firstly, it is important to note that the model is still in the early stages of development. This paper suggests that the method can be developed for use in industry as a predictive tool in order for suitable policy planning; however significant further testing is required. The input variables can be specifically manipulated in order to represent different systems. However the results generated by this study are limited due to the use of only a small amount of real life based around one event. Despite this, the study shows significant potential for this use of system dynamics.

Within the model, certain variables and flows need to be developed further in order to affect the system more realistically. The most notable of which is the 'Non-Travel Rate,' which should decrease the passenger numbers within the 'demand' stock after a certain level is reached. Similarly, the method for calculating passenger transfer is currently flawed, due to the calculation being directly proportional to the levels of stocks. Similarly, a method of limiting the passenger demand must also be introduced, in order for the demand to remain at a sensible level. 
Development of the model is ongoing and a number of future areas have been identified for development in order for more accurate and reliable passenger distributions to be generated.

- The market for potential travellers must be modelled to limit an excess of demand occurring, this will be investigated through development of a 'Non Travel Rate' as well as development of the 'Transfers' sector.

- The 'transfer rates' must be affected by both the leaving and entering systems, as well as being more accurately defined than just a proportion of the current stock of the leaving system.

- An impact model must be more thoroughly defined than just a simple function of VenSim.

- An impact model could be generated in order for a single impact value to be input, which would then be modified within the model to give impact levels specific to the system being analyzed.

- The model can be increased in order to incorporate more than two transport systems, future iterations intend to include further transport models for coach, light rail and ferry transport systems.

- The stocks of passengers can be disaggregated in order to show the movement of passengers within the system. This will give more detailed information of where passengers are within the system and can clearly show where a build up of passengers exists. For example, within Airports during the Icelandic volcanic eruption.

- Consideration for noise can be included, rather than neglecting their impacts as negligible

Based on these considerations, it can be concluded that using a system dynamics approach to modeling intermodal transport system is suitable and has the potential to demonstrate the rigid behavior caused by the complex interrelationships between the variables.

\section{References}

${ }^{1}$ Davies, G., Price, M., Early, J., Connally, P., (2009) 'Understanding Aspects of Complex systems through an Impact Analysis,' $9^{\text {th }}$ AIAA Aviation Technology, Integration, and Operations Conference (ATIO) AIAA2009-6901, $21^{\text {st }}-23^{\text {rd }}$ September 2009, Hilton Head, South Carolina

${ }^{2}$ Forrester, J. (1961), Industrial Dynamics, John Wiley \& Sons, Cambridge, MA

${ }^{3}$ Abdel Hamid, A. (2002) 'Modelling the dynamics of human energy regulation and its implications for obesity treatment' System Dynamics Review 18:4

${ }^{4}$ Fiddaman, T. (2007) 'Dynamics of Climate Policy,' System Dynamics Review, 23:1, 21-34

${ }^{5}$ Department for Transport (Last updated: $10^{\text {th }}$ June 2011)

http://www2.dft.gov.uk/pgr/statistics/datatablespublications/tsgb/latest/tsgb2010aviation.pdf [Accessed on 21/08/2011]

${ }^{6}$ Department for Transport (Last updated: $10^{\text {th }}$ June 2011)

http://www2.dft.gov.uk/pgr/statistics/datatablespublications/tsgb/latest/tsgb2010public.pdf [Accessed 21/08/2011]

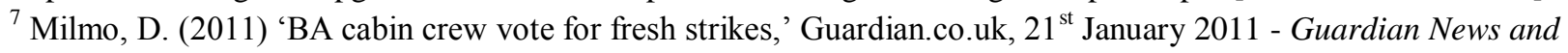

Media Limited http://www.guardian.co.uk/business/2011/jan/21/ba-cabin-crew-strike-vote [Accessed 21/4/11]

${ }^{8}$ BBC News, (2011) 'America's Day of Terror,' British Broadcasting Corporation

http://news.bbc.co.uk/hi/english/static/in_depth/americas/2001/day_of_terror/ [Accessed 20/4/11]

${ }^{9}$ Sherwell, P. (2010) 'Iceland volcano: an eyeful of Eyjafjallajökull' $18^{\text {th }}$ April 2010-Telegraph Media Group

Limited http://www.telegraph.co.uk/news/worldnews/europe/iceland/7601178/Iceland-volcano-an-eyeful-ofEyjafjallajokull.html [Accessed 06/02/11]

${ }^{10}$ Ortúzar, J. de D. and Willumsen, L.G. (1997), Modelling Transport, $2^{\text {nd }}$ ed. John Wiley \& Sons

${ }^{11}$ Davies, G., Price, M., Early, J., Connally, P., (2010) 'The Application of an Agent Based Impact analysis to a Complex Air Traffic Management System,' $10^{\text {th }}$ AIAA Aviation Technology, Integration, and Operations Conference (ATIO) AIAA2010-9256, $13^{\text {th }}-15^{\text {th }}$ September 2010, Fort Worth, Texas

${ }^{12}$ Sterman, J.D. (2000), Business Dynamics: Systems thinking and Modeling for a Complex World, Irwin McGraw Hill, Boston, MA 
${ }^{13}$ Systems Dynamics Society Website (2011) The System Dynamics Society http://www.systemdynamics.org/ [Accessed 10/2/11]

${ }^{14}$ Davies, G., Price, M., Early, J., Connally, P., (2010) 'Understanding Aspects of Air Transportation Systems through an Agent Based Impact Analysis,' AE4414 Airline Operations \& Management 2009-2010

${ }^{15}$ Davies, G., Price, M., Early, J., Connally, P., (2010) 'Understanding Aspects of Air Transportation Systems through an Agent Based Impact Analysis,' Air Transport and Operations Symposium 2010

${ }^{16}$ Ventana Systems, (2010), VenSim Version 5- User's guide, Ventana Simulation Environment- Ventana Systems, Inc

${ }^{17}$ UK Civil Aviation Authority (CAA) (2011) 'Domestic Travel Data' http://www.caa.co.uk/docs/80/airport_data/2010Annual/Table_10_2_Domestic_Terminal_Pax_Traffic_2010.pdf [Accessed 17/8/11]

${ }^{18}$ UK Civil Aviation Authority (CAA) (2011) 'UK Airport Statistics' - Within each Document Directory 2008-10, Table 12,2 - http://www.caa.co.uk/default.aspx?catid=80\&pagetype=88\&sglid=3 [Accessed 17/8/11]

${ }^{19}$ Office of Rail Regulation (ORR) (2011) 'National Rail Trends Yearbook' Chart 1.2b and 7.1 http://www.railreg.gov.uk/server/show/nav.2026 [Accessed 17/8/11] 